Louis Lewin

Durch die USA und Canada

im Jahre 1887

Ein Tagebuch 


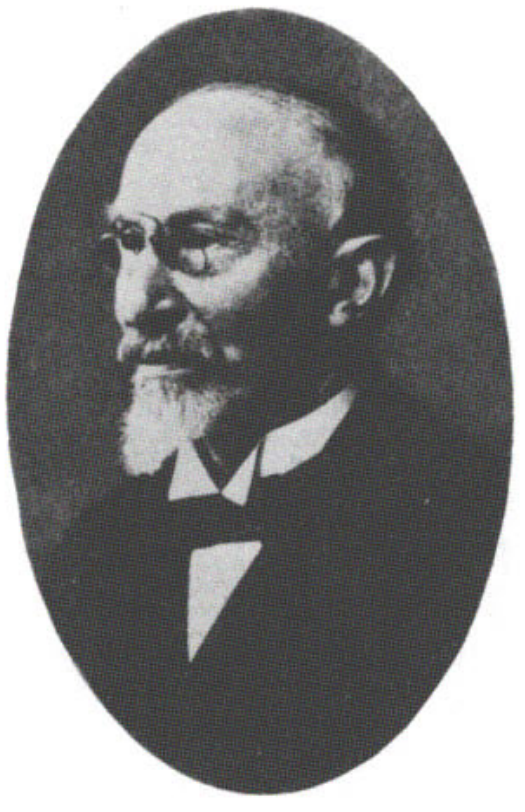

LOUIS LEWIN 


\section{Louis Lewin}

\section{Durch \\ die USA \\ und Canada \\ im Jahre \\ 1887}

Ein Tagebuch

2., unveränderte Auflage

Herausgegeben von

Bo Holmstedt und

Karlheinz Lohs

Akademie-Verlag Berlin

1990 


\author{
Herausgeber : \\ Prof. Dr. Bo Holmstedt \\ Königlich Schwedische Akademie der \\ Wissenschaften \\ Karolinska Institutet \\ Institutionen för Toxikologi \\ Stockholm \\ und \\ Prof. Dr. Karlheinz Lohs \\ Akademie der Wissenschaften der DDR \\ Forschungsstelle für Chemische Toxikologie \\ Leipzig \\ Übertragung der Hahdschrift: \\ Dr. Nolte, Berlin
}

ISBN 3-05-500 576-7

Erschienen im Akademie-Verlag Berlin, Leipziger Straße 3-4, Berlin, DDR-1086

(C) Akademie-Verlag Berlin 1990

Lizenznummer : $202 \cdot 100 / 506 / 90$

Printed in the German Democratic Republic

Gesamtherstellung:

VEB Druckerei „Thomas Müntzer“, 5820 Bad Langensalza

Lektor: Christiane Grunow

Gesamtgestaltung: Ingo Scheffler

LSV 5379

Bestellnummer: 7634190 (6867)

02800 